\title{
Infected left atrial mass within anatomically normal heart
}

\author{
A L A S D I R D. MA L C O L M ${ }^{1}$ and \\ D. MARK CHAPUT DE SAINTONGE \\ Division of Medicine, The London Hospital, Whitechapel, London
}

\begin{abstract}
Malcolm, A. D. and Chaput de Saintonge, D. M. (1975). Thorax, 30, 693-696. Infected left atrial mass within anatomically normal heart. A case is presented with some features of subacute bacterial endocarditis and of left atrial myxoma. Operative removal of a $5 \times 3 \mathrm{~cm}$ tumour lying above and attached to an anatomically normal mitral valve reversed a rapidly deteriorating clinical situation. Histologically the entire tumour appeared to be old thrombus, and Gram-positive cocci in its superficial strata corresponded with Streptococcus viridans previously isolated from blood cultures. Many features, including an eight-year history of intermittent neurological disturbances and recent increasing hypergammaglobulinaemia, accord with the diagnosis of atrial myxoma. However, the valvular attachment site, absence of any cardiac structural abnormality, and tumour histopathology with bacterial colonization of the tumour present a unique situation which is explored in the discussion.
\end{abstract}

Left atrial myxoma can masquerade as infective endocarditis with such features as fever, 'embolic' manifestations, neurological disturbances, and physical signs suggestive of mitral valve stenosis (Harvey, 1968). Echocardiography can now help to sort out such diagnostic uncertainties by detecting intracardiac tumours and evaluating the mitral valve (Martinez, Giles, and Burch, 1974). Herein we describe a case which appeared to be one of infected left atrial myxoma but ultimately proved to be left atrial thrombus attached to an anatomically normal mitral valve.

\section{CASE REPORT}

A 49-year-old decorator presented in the emergency department with a two-week history of night sweats and fever up to $39.4^{\circ} \mathrm{C}$, associated with polyarthralgia affecting knees, elbows, and back, and recent weight loss of 5 kilograms.

At the ages of 14 and 17 he had suffered from rheumatic fever, and eight years before admission he had experienced evanescent right-sided weakness and paraesthesiae associated with dysphasia. On one occasion a loud first heart sound and a faint mid-diastolic murmur were

'Present address: Biophysics Department, Faculty of Medicine, University of Western Ontario Health Sciences Centre, London, Ontario, Canada noted. Six months before admission he had several teeth extracted without antibiotic cover.

On examination he was an ill-looking man with a temperature of $40^{\circ} \mathrm{C}$, with many carious teeth and extensive periodontal disease. The blood pressure was $110 / 70 \mathrm{mmHg}$, the pulse $98 /$ minute and regular, and the jugular venous pressure was not elevated. The left radial pulse was reduced. The first heart sound was loud, and the second heart sound was normal with no added sounds or murmurs. Tenderness was present over the slightly enlarged liver and in the hypochondrium.

Investigation revealed an erythrocyte sedimentation rate of $32 \mathrm{~mm}$ in the first hour (Westergren), haemoglobin $12 \cdot 1 \mathrm{~g} / \mathrm{dl}$, white cell count $17400 / \mathrm{mm}^{3}$ with a polymorphonuclear leucocytosis, serum globulins $3.6 \mathrm{~g} / \mathrm{dl}$ with electrophoresis showing a polyclonal increase in the gamma fraction. The serum aspartate aminotransferase and lactic dehydrogenase were mildly elevated with normal bilirubin and alkaline phosphatase levels. The urine contained occasional granular casts but no red cells and was sterile on culture, as were three blood cultures. A chest radiograph showed a normal cardiac silhouette with a cardiac size at the upper limit of normal; the lung fields were clear.

An electrocardiogram recorded 15 months earlier was available showing sinus rhythm with 
$P$ wave duration $0.12 \mathrm{sec}$ with a prominent negative P-terminal vector in lead V1 compatible with left atrial enlargement. In comparison, the electrocardiogram on admission showed a general reduction in voltage and a $\mathbf{P}$ wave of less abnormal form with the P-terminal force in V1 less prominent. The QRS axis was similar but the $T$ axis showed a shift leftwards compared with the earlier tracing.

Three days after admission the patient developed an Osler's node on the pulp of a middle finger and bilateral knee effusions; the lesions were sterile. Streptococcus viridans grew in six of six further blood cultures. Benzyl penicillin, $3 \times 10^{6}$ units intramuscularly, plus probenecid, $0.5 \mathrm{~g}$ orally every 6 hours, were started, achieving trough plasma penicillin levels well above 10 times the minimum inhibitory concentration for the organism.

Twenty days after admission he was still febrile with rising serum globulin levels and erythrocyte sedimentation rate, and several episodes of transitory central chest pain had occurred. Now a pathologically loud first heart sound, an extra sound shortly after P2, and a faint apical pansytolic murmur were heard. An echocardiogram (Fig. 1) was performed forthwith, demonstrating a mass in the left atrium. A presumptive diagnosis of infected left atrial myxoma was made. Penicillin was continued but fever persisted, and 37 days after admission the patient experienced sudden severe chest pain radiating down the left arm, and severe dyspnoea. The electrocardiogram showed non-specific changes with

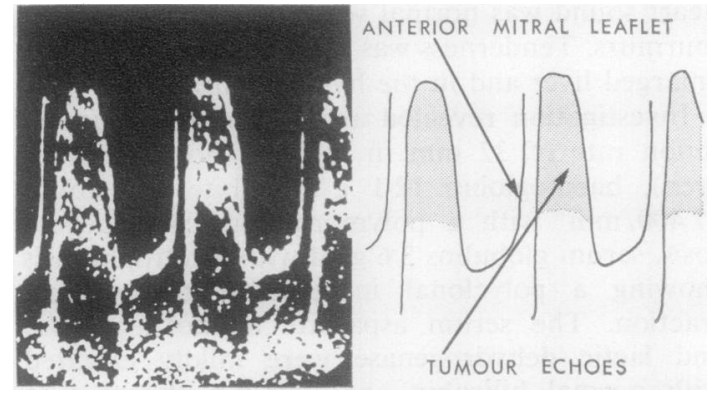

FIG. 1 The preoperative mitral valve echogram shows a dense cloud of echoes behind the anterior mitral leaflet in diastole. The opening movement of the anterior mitral leaflet is seen as a sharp upstroke echo line clearly separated from the main cloud of tumour echoes, showing that the tumour enters that part of the mitral orifice transgressed by the echo beam a little after mitral valve opening has occurred.

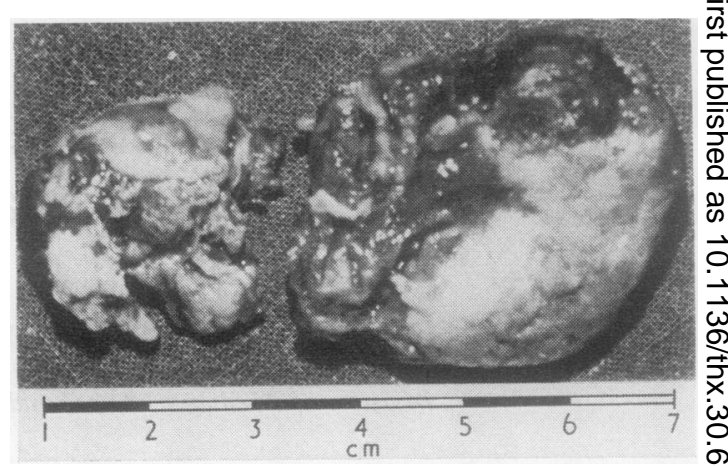

FIG. 2. The tumour immediately after its removalo in two parts from the left atrium, wherein that parte of the tumour seen on the left constituted its pedicleo of attachment to the posterior mitral leaflet close to the medial commissure.

a $30^{\circ}$ leftward shift in QRS axis to $+40^{\circ}$ witlo the $\mathrm{T}$-wave axis remaining at about $+10^{\circ}$. Angio足 graphy revealed a filling defect in the left atriumand the patient proceeded to surgery the same day.

At operation (Mr. E. J. M. Weaver) the lef atrium was opened under cardiopulmonary bypass and an irregular, globular, partly necrotico $5 \times 3 \mathrm{~cm}$ yellowish-brown mass was exposed. Thळू tumour (Fig. 2) had a rubbery consistency an\& was attached by a short, thick pedicle to a smalf area on the atrial aspect of the posterior mitra $B$ leaflet close to the medial commissure. The attachment was readily severed at the valve sur? face, and the mitral valve, left atrium, aortic valve, and all visible endocardium seemed entirels normal. Postoperatively penicillin was continued and once a left lower lobe pneumonia had resolved, the patient became consistently afebrile $\mathrm{He}$ was discharged symptom-free on the $23 \mathrm{r} \$$ postoperative day.

PATHOLOGICAL REPORT The mass was composed throughout of solid yellowish-brown tissue witle. its irregular shiny surface deficient in one areß్ where friable necrotic material was exposed. On microscopy the substance of the mass proved to be acellular homogeneous densely staining eosinow philic material in which silver stains for reticulise showed evidence of organization without the presence of fibrous tissue. Fibrin was demon strable by special staining. Small foci of calcification were present. The Gram's stain demonstrated numerous Gram-positive cocci, some aligned i loose chains, in the superficial layers. It wa\& concluded that the mass was composed of ol\$ 
thrombus with evidence of superficial bacterial infection without any suggestion of myxoma or malignant tumour of other type.

\section{DISCUSSION}

The background history, early clinical course in hospital, and isolation of Str. viridans from blood cultures favoured the initial diagnosis of subacute bacterial endocarditis in this patient. From the time of echocardiographic diagnosis of intracardiac tumour until the final verdict on its histopathology it seemed that the problem was one of infected left atrial myxoma; we are aware of three previously reported cases (Malloch, Abbott, and Rapaport, 1970). With evidence of embolization we presumed the tumour to be necrotic and supposed that the exposed necrotic areas had been susceptible of streptococcal colonization during the recent teeth extractions. Chest pain and the electrocardiographic changes were ascribed to possible embolic coronary artery plugging, as reported by Horder (1909).

The inconstancy of systolic and diastolic murmurs with left atrial myxoma is affirmed in standard texts and by Goodwin (1963) and Luisada (1973); in this patient it first suggested the possibility of left atrial tumour. Changing murmurs also occur in endocarditis but are by no means typical (Rabinovich, Smith, and January, 1968). Horder (1909) remarked that in chronic infective endocarditis undue importance is perhaps attached to the changes heard in the character of the murmurs from day to day. $\mathrm{He}$ considered that these changes do occur but are not of great importance and that they relate more to acute endocarditis or chronic endocarditis without infection.

The attachment of the thrombus and its mode of genesis within an anatomically normal heart are puzzling. Nearly all atrial myxomas arise from the inter-atrial septum (Hudson, 1965), but among 49 cardiac myxomas cited by Prichard (1951) one arose on a valve. Prichard also mentions five mitral valve fibromas, tumours described as papillary, pedunculated, villous masses overlaid by endothelium and composed of acellular hyaline fibrous tissue, sometimes avascular. Does the fact that the thrombus was pedunculated suggest that originally there was a small pedunculated tumour which provided a focus for gradual accretion of thrombus? In the early part of this century myxomas were thought to be thrombi undergoing myxomatous degeneration, but Yater (1931) and Prichard (1951) effectively established the current opinion that they are true neoplasms. The anatomical normality of the mitral valve in one case of pedunculated left atrial tumour described as a 'pseudo-myxoma' and believed to be thrombus (Hamilton-Paterson and Castleden, 1942) did not receive specific comment. Perhaps the absence of tumour cells in our patient was the result of such original cells having been effaced with the passage of time or shed from the original core of the tumour in an embolic disintegration. The alternative hypothesis is that a thrombotic vegetation developed on the posterior leaflet of the mitral valve and by some remarkable process the thrombus grew, retaining its pedicle. The mechanism of vegetation formation in endocarditis remains mysterious (Hayward, 1973) and the gross normality of the mitral valve need not preclude original vegetation formation, for endocarditis can occur on an undoubtedly normal valve as, for instance, in six of the patients reported by Hughes and Gauld (1966).

A definitive conclusion on the pathogenesis of this patient's tumour is impossible. The history of transient neurological disturbances extending back eight years and abnormal auscultatory findings five years before admission seem more in line with the behaviour of an atrial myxoma. The superficial stratification of the tumour with chains of Gram-positive cocci suggest that accretion of thrombus was occurring more recently. Continuing clinical deterioration in spite of good blood penicillin levels highlights the need for extirpation of sequestrated infection. In this patient open operation secured not only immediate haemodynamic improvement by removal of the obstruction but also eliminated the focus of infection.

The authors thank Professor D. W. Vere and Mr. E. J. M. Weaver for permission to report this patient, and Dr. W. C. Roberts of the National Heart and Lung Institute, Bethesda, Maryland, USA, who kindly reviewed the histological slides.

\section{REFERENCES}

Goodwin, J. F. (1963). Diagnosis of left atrial myxoma. Lancet, 1, 464.

Hamilton-Paterson, J. L. and Castleden, L. I. M. (1942). Intracardiac tumours. British Heart Journal, 4, 103.

Harvey, W. P. (1968). Clinical aspects of cardiac tumours. American Journal of Cardiology, 21, 328.

Hayward, G. W. (1973). Infective endocarditis: a changing disease-I. British Medical Journal, 2, 706. 
Horder, T. J. (1909). Infective endocarditis. Quarterly Journal of Medicine, 2, 289.

Hudson, R. E. B. (1965). Cardiovascular Pathology. Edward Arnold, London.

Hughes, P. and Gauld, W. R. (1966). Bacterial endocarditis: a changing disease. Quarterly Journal of Medicine, 35, 511.

Luisada, A. A. (1973). The Sounds of the Diseased Heart. W. H. Green, St. Louis.

Malloch, C. I., Abbott, J. A., and Rapaport, E. (1970). Left atrial myxoma with bacteremia. American Journal of Cardiology, 25, 353.

Martinez, E. C., Giles, T. D., and Burch, G. E. (1974). Echocardiographic diagnosis of left atrial myxoma. American Journal of Cardiology, 33, 281.
Prichard, R. W. (1951). Tumors of the heart. Archives of Pathology, 51, 98.

Rabinovich, S., Smith, I. M., and January, L. E. (1968). The changing pattern of bacterial $\bar{\omega}$ endocarditis. Medical Clinics of North America, 52, 1091.

Yater, W. M. (1931). Tumors of the heart and pericardium. Archives of Internal Medicine, 48, $\overrightarrow{\mathrm{O}}$ 627.

Requests for reprints to: Dr. A. D. Malcolm, Biophysics Department, Faculty of Medicine, University of Western Ontario Health Sciences Centre, London, Ontario, Canada. 